\title{
Cuantificación de sílice presente en el follaje de guadua angustifolia Del departamento del Quindío
}

\author{
Quantification of silicon of foliage of guadua angustifolia \\ From the Quindío
}

\author{
Carolina Herrera-Giraldo*, Milton Gómez Barrera**, Maricela Saavedra Hernández***, \\ Gerardo Fonthal Rivera $* * * *$, Victoria Eugenia Gonzalez Ceballos****, Hernando Ariza Calderón****
}

Recibido: Marzo 15 de 2009

Aceptado: Septiembre 30 de 2009

Correspondencia: Cra. 15 Clle. 12N Universidad del Quindío, Instituto Interdisciplinario de las Ciencias, Semillero de Investigación en Guadua.

\section{RESUMEN}

Se presenta un estudio sobre la cuantificación del Sílice en el follaje de Guadua angustifolia. Por técnicas gravimétricas se encontró que el porcentaje de Sílice en "El Sendero Cedro Rosado" fue de 2.59\% en base seca, en ceniza, mientras que la muestra procedente de la Reserva Natural "La Montaña del Ocaso" tiene una concentración de 1.70\%. Mediante el SEM y por microscopía de fluorescencia avanzada, se obtuvo que el Sílice se deposita en los haces vasculares de la hoja y en menor proporción entre las células largas. Dado que la densidad de las células silíceas disminuye desde el centro de la hoja hacia los bordes y hacia el ápice, concluimos que la presencia del Sílice en la parte foliar de la G. angustifolia tiene funciones de estabilidad mecánica de los tejidos.

Palabras clave: Guadua angustifolia, Poaceae, hoja, cuantificación de sílice, Quindío, SEM, técnicas gravimétricas, microscopio de fluorescencia.

\section{ABSTRACT}

A study about silica quantification in the bamboo foliage of Guadua angustifolia is presented. Through gravimetric techniques, it was found that silica percentage at the "Sendero Cedro Rosado" was $2.59 \%$ in dry weight basis (in ash), while the sample from the Natural Reserve "La Montaña del Ocaso" had a concentration of 1.70\%. Through SEM and advanced fluorescent microscopy, it was found that Silica is deposited in the vascular bundles of the leaves and in lesser proportion within large cells. Due to the diminishing of the density of the silica cells from the center toward the edges and apexes, we concluded that the presence of Silica in the bamboo foliage of Guadua angustifolia has functions of tissue mechanic stability.

Keywords: Guadua angustifolia, Poaceae, leaf, Silica quantification, Quindío, SEM, gravimetric techniques, fluorescent microscopy.

\section{INTRODUCCIÓN}

U no de los compuestos químicos que se encuentra en mayor concentración en la familia Poaceae es el Sílice, y esta densidad es una de las características más predominantes en dicha familia (Motomura, 2004). Las investigaciones químicas de las gramíneas han demostrado que el Sílice se deposita en los tejidos de las hojas y en las inflorescencias y su acumulación aumenta significativamente durante su desarrollo, hasta alcanzar su madurez (3 años), continuando con un leve aumento en la senescencia (Motomura, 2002). continuando con un leve aumento en la senescencia (Motomura, 2002).

Se conocen como cuerpos silíceos aquellos discretos depósitos de Sílice en las células silíceas de la epidermis. Estos cuerpos sólidos opalinos o fitolitos de ópalo tienen formas diversas y se depositan en el lumen de los idioblastos o células silíceas específicas y especializadas en diferentes proporciones según el tipo de planta; las gramíneas, por ejemplo, pueden acumular diez o veinte veces más cantidad de fitolitos que las leguminosas (Jones \& Handreck, 1965 citado en Londoño \& Kobayashi, 1991).

\footnotetext{
* Investigadora, Semillero de Investigación en Guadua, Instituto Interdisciplinario de las Ciencias, Universidad del Quindío,

** Laboratorio Química Analítica, Programa de Química, Universidad del Quindío,

*** Semillero de Investigación en Guadua Instituto Interdisciplinario de las Ciencias, Universidad del Quindío,

**** Instituto Interdisciplinario de las Ciencias, Universidad del Quindío.
} 
Estos fitolitos se dan como resultado de la absorción del Sílice del suelo por medio de la hidratación en forma de ácido silicílico y es acumulado, según Motomura et al. (2005), en mayor concentración en la parte aérea como Sílice hidratado amorfo. Además, se ha propuesto que la absorción es controlada por la planta hacia el incremento de la estabilidad mecánica de sus tejidos (Balasta et al., 1989, citado en Motomura, 2002) y para suministrar protección contra microorganismos y algunos herbívoros (Belanger et al., 1995, Marscher, 1995).

En el género Guadua, al que pertenece la Guadua angustifolia Kunth, los cuerpos silíceos presentan la típica forma de silla de montar, verticalmente elongados, estrechos en la parte media y anchos en el extremo superior e inferior, presentando una marcada prominencia en ambos extremos (Londoño \& Kobayashi, 1991).

El presente estudio pretende cuantificar el Sílice de las hojas de la G. angustifolia y precisar la ubicación de éste dentro de la misma, mediante la utilización de técnicas gravimétricas, rayos X, Microscopio Electrónico de Barrido (SEM) y Microscopio de Fluorescencia Avanzada.

\section{MATERIALES Y MÉTODOS}

\section{Material vegetal:}

Las muestras de follaje de $G$. angustifolia fueron colectadas a partir de Guaduas en edades de corte (tres y cinco años) en La reserva natural "“La Montaña del Ocaso"", la cual es una selva secundaria intervenida que se encuentra ubicada en el Municipio de Quimbaya, departamento del Quindío, entre las cordilleras central y occidental de la región Andina Colombiana; a una altitud que oscila entre 975 y 1100 m, entre los $4^{\circ} 34^{\prime}$ Latitud Norte, y $75^{\circ} 51^{\prime}$ Longitud Oeste. Tiene una precipitación de $1691 \mathrm{~mm} / \mathrm{año}$, una temperatura media de $24^{\circ} \mathrm{C}$ y una humedad relativa de $76 \%$. También se colectaron muestras de "El Sendero Cedro Rosado", el cual es un bosque húmedo con árboles de gran porte y guaduales que se encuentra ubicado en la ciudad de Armenia, a una altitud de 1490 a $1530 \mathrm{~m}$, entre los 4ㅇ 32 ' latitud norte y 750 40 'longitud oeste, con una temperatura promedio de 19.5 oC, una precipitación de $2436 \mathrm{~mm} /$ año y una humedad relativa de $65-75 \%$. Estas muestras fueron prensadas, secadas y trituradas para los análisis posteriores.

\section{Gravimetría:}

La cuantificación de Sílice en las cenizas de follaje de $G$. angustifolia, se realizó mediante la técnica de determinación de cenizas y de cenizas sulfatadas en carotenos propuesta por Gaviria y Calderón (1988) y adecuadas para nuestras muestras. Se pesaron $5.0000 \mathrm{~g}$ de material vegetal previamente desecado y triturado. Luego, con ayuda de una pequeña llama, se calentaron hasta obtener un producto carbonoso al cual se le agregaron $2.0 \mathrm{~mL}$ de ácido sulfúrico. Posteriormente, se pasó a la mufla y se calcinó a $700^{\circ} \mathrm{C}$ durante siete horas. De estas cenizas sulfatadas se tomaron $0.2000 \mathrm{~g}$ y se les hizo digestión con $10.0 \mathrm{~mL}$ de ácido clorhídrico y $3.0 \mathrm{~mL}$ de ácido nítrico. Finalmente, por análisis gravimétrico se obtuvo el porcentaje de Sílice.

\section{Análisis microscópico y rayos $\mathrm{X}$ :}

Se utilizó el microscopio electrónico de barrido (SEM; JEOL 5910 LV) para las observaciones de las células silíceas en la superficie adaxial y abaxial de la hoja seca y madura de $G$. angustifolia, cubierta con oro y dividida en tres secciones: basal, media y apical.

Para la identificación de las células silíceas a nivel tisular, se utilizó el microscopio de fluorescencia avanzada (Olympus IX81 invertido). Se hicieron cortes longitudinales y transversales del follaje e inmediatamente, se montaron al microscopio sin ningún tratamiento.

Los patrones de difracción de rayos $X(\operatorname{DrX})$ fueron registrados usando un difractómetro Bruker D8 advance con radiación $\mathrm{Ka}$ $\mathrm{Cu}(35 \mathrm{kV}, 30 \mathrm{~mA})$ tamaño de paso de $0.01^{\circ}$ y $3 \mathrm{~s}$ por paso sobre el rango de $10^{\circ}<2 \theta<45^{\circ}$.

Análisis estadístico: Para el análisis e interpretación de los resultados del análisis gravimétrico, se utilizó un análisis de varianza con el fin de comparar la concentración de Sílice de acuerdo con los porcentajes obtenidos en el follaje de $G$. angustifolia en ambos sitios de muestreo. Esta prueba se efectuó usando el programa STATGRAPHICS PLUS versión 5.0.

\section{RESULTADOS Y DISCUSIÓN}

Determinación de la composición de Sílice mediante el análisis gravimétrico. Mediante el resultado obtenido por la técnica de gravimetría en las cenizas del follaje de la $G$. angustifolia, se pudo conocer que la muestra procedente del "Sendero Cedro Rosado", presentó una mayor concentración de Sílice con un valor de $2.59 \%$, mientras que la muestra procedente de la Reserva Natural "La Montaña del Ocaso" tiene una concentración de $1.70 \%$. Motomura et al. en el año 2000 reportó para la especie Pleioblastus chino un alto contenido de Sílice, con un total entre $8.4 \%$ y $12.7 \%$; Zhen-ji, et al. en el 2006 reportó en el Moso bamboo un porcentaje de Sílice de $3.10 \%$, igualmente, se determinó que para tres especies del género Phyllostachys valores entre $4.52 \%$ y $13.74 \%$ (Dayton y Hames, 2000) y para el Phyllostachy heterocycla Mitf el porcentaje de $7.3 \%$ en la epidermis de las hojas (Lux et al., 2003). 
Según el análisis de varianza en los porcentajes de concentración de cenizas para la variable sitio (fig. 1), las muestras colectadas en "El Sendero Cedro Rosado" presentan un mayor porcentaje de Silicio con un 130\%, mientras que las muestras de la Reserva Natural "La Montaña del Ocaso" un $90 \%$, con un valor p-value de 0.0002 .

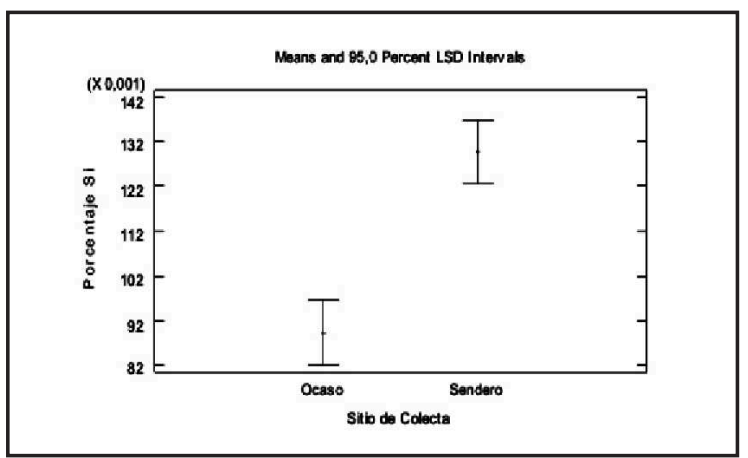

Figura 1. Análisis de varianza en las cenizas del follaje de la G. angustifolia.

A partir del análisis gravimétrico se muestra que la presencia del Sílice en las hojas de guadua depende críticamente del sitio geográfico, hecho éste que debe ser importante al momento que se tomen decisiones económicas para la industrialización con fines farmacéuticos del Sílice orgánico.

\section{Difracción de Rayos $X$}

Los resultados de los patrones de difracción de rayos $X$ (fig. 2) tomados en las cenizas del follaje, presentan halos amorfos alrededor de 22 2è, los cuales corresponden al máximo de difracción para el Oxido de Silicio. Lo anterior, se constituye en el principal componente mineral de ambas muestras. Estos resultados concuerdan con lo propuesto por Motomura et al. en el 2002, para el bambú. El resultado de Rayos X, confirma sin ambigüedad la presencia del Sílice en la parte foliar de la guadua, determinándose con este análisis que este mineral es el que está en mayor proporción en la hoja de la gramínea.

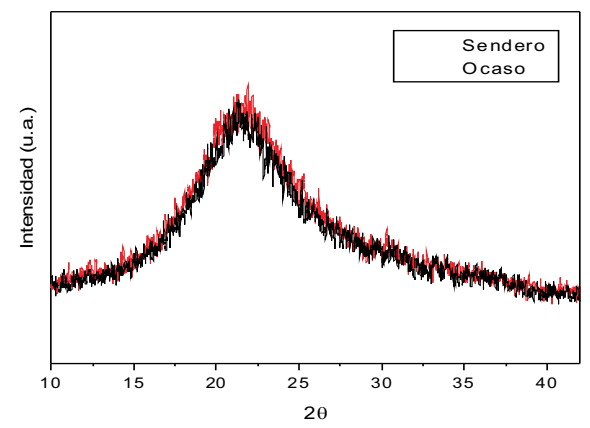

Figura 2. Patrones de difracción de rayos $X$ sobre el rango de $10^{\circ}<2 \theta<45^{\circ}$ en la $G$. angustifolia de dos sitios de colecta.

\section{Microscopía}

Como método alternativo, frente a los que se emplearon en la cuantificación de Sílice y cuyos resultados son reportados con anterioridad; tanto el SEM como el microscopio de fluorescencia avanzada, se emplearon para la observación de las células Silíceas en la superficie de la hoja y a nivel tisular, respectivamente. Por medio del microscopio de fluorescencia avanzada se logra observar que la hoja madura de G. angustifolia tiene varios tipos de células. Una capa de células de la epidermis adaxial, una capa de mesófilo (clorénquima, células fusionadas y parénquima) y una capa de células de la epidermis abaxial. Los haces vasculares están rodeados por células del parénquima e intercalados entre las células del mesófilo. Las células del esclerénquima se prolongan desde el haz vascular hasta la epidermis dorsal (fig. $3 A)$.

Las epidermis se encuentra acompañada por cinco tipos de células: células buliformes; dos células de guarda u oclusivas rodeadas de células acompañantes que forman los estomas (fig. $3 \mathrm{~A}$ ); células largas; las células silíceas que pueden llegar a depositarse entre las células largas (fig. 3B) y los tricomas espinosos (fig. 4A).
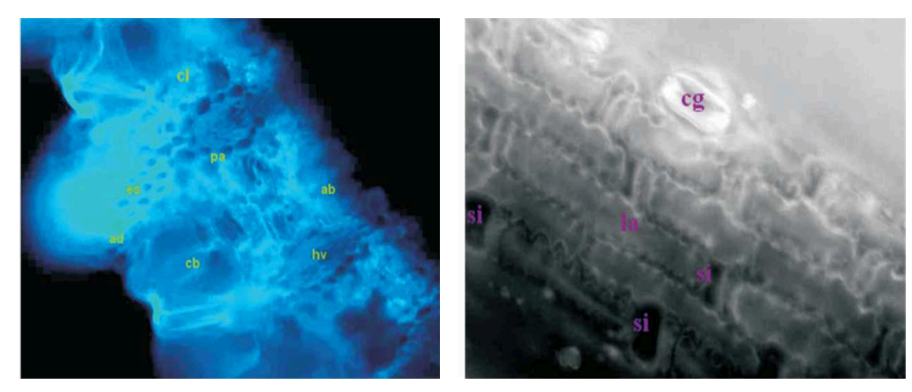

Figura 3. Sección transversal (A) y longitudinal (B) de hoja seca y madura de $\mathrm{G}$. angustifolia observadas usando un microscopio de fluorescencia avanzada. ad, Epidermis adaxial; cl, Clorénquima; fu, Células fusionadas; pa, Parénquima; ab, Epidermis abaxial; hv, Haces vasculares; es, Células del esclerénquima; $c b$, Células buliformes (cb); cg, Células guarda o estomas; si, Células silíceas.

Mediante imágenes tomadas en el SEM (scanning electron microscope), se observó que las células de Sílice tienen forma de silla de montar (fig. 4B), con una longitud a lo largo del eje central entre $4.89 \mathrm{im}$ y $10.21 \mathrm{ìm}$ y un ancho que varió entre $11.25 \mathrm{ìm}$ y $17.58 \mathrm{ìm}$ las cuales se distribuyen regularmente en la epidermis de la hoja en filas sobre el nervio central.

Los cuerpos silíceos del género Guadua presentan la típica forma silla de montar de las Bambusoideae, verticalmente elongadas, con una longitud que varía entre $11.8 \mu \mathrm{m}$ y $18.2 \mu \mathrm{m}$ y un ancho entre $5.2 \mu \mathrm{m}$ y $7.5 \mu \mathrm{m}$ (Londoño \& Kobayashi, 1991). 
Al igual que los resultados aquí obtenidos en relación con la distribución de las células de sílice, Lux, et al., 2003, muestran iguales resultados en el bambú. A saber, dicen ellos que "La distribución de las células silíceas de las hojas del bambú Phyllostachys heterocycla se distribuyen en la epidermis en filas sobre las venas".

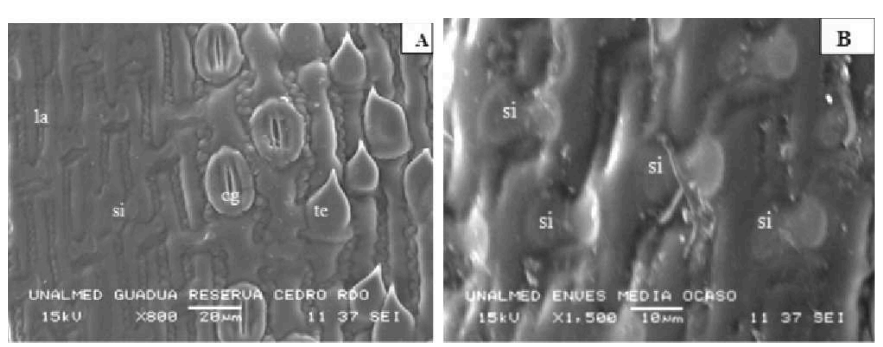

Figura 4. Superficie abaxial ( $\mathrm{A}$ y $B$ ) de la hoja madura de G. angustifolia. cg, Células guarda o estomas; te, Tricomas espinosos; si, Células silíceas; la, Células largas mediante el microscopio electrónico de barrido (SEM).

A la luz de los resultados aquí obtenidos, se observan unas diferencias en las concentraciones de sílice de las muestras tomadas tanto en la reserva natural "La Montaña el Ocaso" como en "El Sendero Cedro Rosado". Para la determinación de estos factores se implicarían otra serie de estudios tales como, estudios de suelos (que permita determinar la cantidad de sílice disponible), un estudio de biomineralización, así mismo, un estudio pormenorizado de las condiciones micro-climáticas, es decir, nivel freático, pluviosidad, brillo solar, temperatura, humedad relativa, si se pretende obtener potenciales valores y usos económicos.

\section{CONCLUSIONES}

*Por las técnicas de gravimetría y espectrofotometría de absorción atómica, se pudo conocer que la muestra procedente de "El Sendero Cedro Rosado" presentó una mayor concentración de Sílice en relación con la muestra procedente de la Reserva Natural "La Montaña del Ocaso", lo que indica en principio que el sitio geográfico es importante para la absorción del sílice.

* Mediante el DRX se observa que las cenizas presentan halos amorfos alrededor de $22^{\circ} 2 \theta$, los cuales corresponden al máximo de difracción para el Oxido de Silicio; determinándose con eso, sin ambigüedad, que el $\mathrm{Si}$ es el principal elemento mineral en la hoja de Guadua.

**Mediante imágenes tomadas en el SEM (scanning electron microscope), y por el microscopio de fluorescencia avanzada se observó que las células de Sílice tienen forma de silla de montar, con una longitud a lo largo del eje central entre $4.89 \mu \mathrm{m}$ y $10.21 \mu \mathrm{m}$ y un ancho que varió entre $11.25 \mu \mathrm{m}$ y $17.58 \mu \mathrm{m}$ las cuales se distribuyen regularmente en la epidermis de la hoja en filas sobre el nervio central, dándole posiblemente fortaleza estructural a la hoja.

\section{BIBLIOGRAFÍA}

Belanger RR, Bowen PA, Ehret DL, y Menzies JG. "Soluble silicon. Its role in crop and disease management of greenhouse crops". Plant disease. 1995; 79. 329-336.

Gaviria LE, Calderón CE. Manual de métodos analíticos para el control de calidad en la industria alimentaria. Bogotá, Colombia. Instituto Colombiano de Normas Técnicas ICONTEC. 1988.

Londoño X, Kobayashi M. (1999). “Estudio comparativo entre los cuerpos silíceos de Bambusa y Guadua”. Caldasia. $1991 ; 16$. 407-418.

Lux A, Luxová M, Abe J, Morita S, Inanaga S. "Silicification of bamboo (Phyllostachys heterocycla Mitf.) root and leaf". Plant and Soil, 2003; 255. 85-91.

Marschner H. "Mineral nutrition of higher plants". 2a Ed. San Diego: Academic Press; 1995. p 430-445.

Motomura H, Mita N, Suzuki M. "Silica accumulation in long-lived leaves of Sasa veitchii (Carrière) Rehder (Poaceae: Bambusoideae)". Ann Bot. 2002; 90. 149-152.

Motomura H, FUJII T, SUZUKI M. "Silica Deposition in Relation to Ageing of Leaf Tissues in Sasa veitchii (Carrière) Rehder (Poaceae: Bambusoideae)". Ann Bot. 2004; 93. 1-14.

Motomura H, FUJII T, SUZUKI M. "Silica Deposition in Abaxial Epidermis before the Opening of Leaf Blades of Pleioblastus chino (Poaceae, Bambusoideae)". Ann Bot. 2005; 97. 513-519.

Scurlock JMO, Dayton DC, B Hames.. Bamboo: an overlooked biomass resource?. Publication No. 4963. Oak Ridge, Tennessee. Environmental Sciences Division, 2000.

Zhen-ji L, Peng L, Jian-Yuan H, Zhi-wei Y, Yi-Ming L. (). "Silicon's organic pool and biological cycle in Moso bamboo community of Wuyishan Biosphere Reserve". J Zhejiang Univ SCIENCE B. 2006; 11. 849-857. 